\title{
Towards A Multilingual Learner for African languages
}

\author{
Frederick K. Iraki E Charles R. Maroa
}

\begin{abstract}
I. Introduction
Kenyan universities, in particular the University of Nairobi, have been for the last five or so years been a beehive of research around speech technologies with respect to Kenyan languages. In 2004, Dr. Muchemi Gakuru (principal investigator), Dr. Frederick Iraki (computational linguist) and Mr. Kamanda Ngugi (Computer scientist) broke new research ground by producing the first Kiswahili Text-To-Speech computer system in the world (Mucemi et al. 2004). The software can read any text typed in Kiswahili and therefore presents myriad advantages to the visually-handicapped, language learning and teaching, persons with voice impairment, just to mention a few (Ngugi 2004). It is important to note that Text-to-Speech systems for other major world languages (English, French, Chinese, etc.) were already in place.
\end{abstract}

In 2005, while consulting for Zi-Corp, Dr. Iraki designed a database with Microsoft Access to enable a C+ program create Kiswahili words and sentences. The software was to be used on Sony Eriksson mobile phones. The database was structured using several layers of composition or incremental particles that ultimately build the Kiswahili language. The results were then checked using a standard Kiswahili dictionary to verify the efficiency of the database. The research was rewarded with an $85 \%$ score by the electronic dictionary.

The experienced garnered from designing the database for the words and sentences presented an opportunity to unpack the Kiswahili language and begin to wonder whether the same database could be tinkered with to create other Bantu languages such as Gikuyu, Kamba, Giriama, Zulu, etc. For instance, kiti (chair) in Kiswahili can be modified through letter substitution of $k$ by $g$ to produce giti (chair) in Gikuyu language. In addition, many words especially in the N-N class ${ }^{1}$ in Kiswahili are more less the same in Kenyan Bantu languages. These include nyumba, meza, motokaa, kompiuta, redio, etc. Similarly, some languages may require deletion, or augmentation of a Kiswahili substratum to produce them. Once the languages have been compared and contrasted, we can then design appropriate substitution, deletion and incremental rules to enable a shift from Kiswahili to any Bantu language, and vice-versa.

As a first humble step toward unfurling the cross-translational project, we decided to begin by developing online multilingual software for learning Kenyan languages. The aim of the project was to harvest a sizeable number of Bantu words and sentences to inform our research on Bantu database design. Another important aim was to generate interest among Kenyans, especially the youth, to learn each other's language, thus promoting peace-building and appreciating Kenya's cultural and linguistic diversity.

${ }^{1}$ This is the biggest noun class in Kiswahili. 


\section{Rationale}

Although the world is on the verge of relying entirely on digital devices for its affairs, Africa and indeed Kenya continues to lag behind in the domain of innovation. The first Kiswahili Text-to-Speech system that we developed was greeted with great suspicion and incredulity by both the academia and the industry. Despite the various demonstrations conducted, Kenyans showed awe and interest for a while then turned the other way. The software was developed as an open source resource and therefore remains available on the Internet for use or adaptation (http://www.llsti.org). The research was funded by DFID under the Local languages Speech Technology Initiatives (llsti). Locally, the software is hardly used, let alone talked about in schools or industry.

\section{Lack of innovation in school and university curriculum}

The cynicism toward innovation could find its roots in our educational system and its colonial trappings. Whereas the colonial educational system in Kenya was geared toward serving the interest of Imperial Britain and particularly the white settler community the reforms in the Ominde Commission of 1964 ushered in a new educational dispensation to cater for Black interests. Forty years later, it is now abundantly clear that the current educational system has little if any room for critical thinking, autonomy and innovation. Instead, it has produced generations of rotelearners who score A's in examinations with neither the capacity for any critical reflection, nor any ability to create jobs for themselves.

The products of our educational system have imbibed tons of Western cultural propaganda from the print and electronic media, propaganda that subliminally promote Western intellectual and cultural dominance to the detriment of other cultures. As a result, we have successfully produced a generation that derides anything African and celebrates anything Western. The situation is critical in the digital world where few if any Kenyans are ready to venture into designing computer software.

Through innovation, we can begin to participate in the digital world as players not spectators. Innovation can also be crucial in both mercantile and social entrepreneurship to better our lives in Kenya. The former creates business opportunities for lucre while the latter aims at promoting social and environmental harmony for the less privileged. But why develop a multilingual learner?

\section{Justification for a Multilingual learner}

Kenya had 42 odd ethnic communities with almost the same number of tongues if not more. The 42 groups fall in bigger language clusters namely Bantu, Nilotic and Cushitic. Is there a possibility of designing software that can be employed to enhance cross-cultural dialogue? Could such software also help the youth in urban areas learn their own indigenous language? The urban youth mainly use Kiswahili, Sheng ${ }^{2}$ or English and therefore do not know or indeed know very little mother of father tongue.

\section{Aims of the multilingual learner}

Although this is only the first part toward developing comprehensive software for cross-linguistic translation in Kenyan languages, the multilingual learner as it stands currently has the following aims:

\footnotetext{
${ }^{2}$ Sheng is a sub-language comprising Kiswahili syntax but a motley lexicon from Kiswahili, Arabic,
} English and other local Kenyan languages (Abdulaziz et al. 1997, Githiora, 2002, Iraki 2004) 
- Avail an electronic tool portable to computers and especially mobile phones that can help a person learn a Kenyan language at any time any place;

- Promote inter-ethnic dialogue and peace via linguistic appreciation;

- Promote literacy in local languages;

- Create opportunities for entrepreneurship.

Uses of the multilingual learner

The learner will have many uses as follows:

\section{Language learning}

The multilingual learner will enable a potential client to choose the language they want to learn in the computer or mobile phone and proceed to learn independently since the software incorporates very clear sound files. For starters, the software presents common phrases within several situational paradigms where the learner can select the area of learning. For instance, a tourist may want to be able to say greetings in Giriama while at the Kenyan coast. So, he proceeds to click on Giriama as intended language and English or French as his native language, and then clicks on greetings. The software will now align English (or French) greetings with Giriama greetings. Conversely, a Giriama will be able to start from Giriama and learn English or French. It is hoped that the software will fire off a desire to study Kenyan languages among Kenyans and other people too.

\section{Language study}

By availing data on most Kenyan languages, the project will be a good source of information for academic, students and other persons interested in understanding the dynamics of African languages, and more particularly Kenyan languages. For instance, an American group of scholars ${ }^{3}$ recently wrote to the authors asking for information on Kiswahili and Gikuyu. This project would upload useful research data on languages for such interested groups.

\section{Entrepreneurship}

The multilingual learner presents an opportunity for either open source use or commercial entrepreneurship. In other words, the software can be availed as free ware or refined for the corporate world especially mobile phones. Currently, it is configured to consume negligible memory while maintain clarity of functions as a prelude to porting to mobile phones.

Moreover, in the area of social entrepreneurship, the software can constitute significant contribution in promoting the linguistic knowledge base of Kenyans in disadvantaged areas (Iraki 2006). People in the Northern districts of Kenya can benefit immensely from learning local and international languages. Language knowledge can be an engine of development since communication skills top the list of desirables for employers.

${ }^{3}$ Mary Crookston, Elementary school teacher, Arizona, USA. 


\section{Language fun}

Work and no play make Jack a dull boy. While testing the multilingual learner, we found tremendous joy in just knowing how to say certain things in other Kenyan languages. A strictly utilitarian approach to life might not be so desirable after all. We are also entitled to some amount of fun, even at the detriment of learning. The software will enable people to play around with Kenyan languages, tease each other and basically have a good time.

\section{The project design}

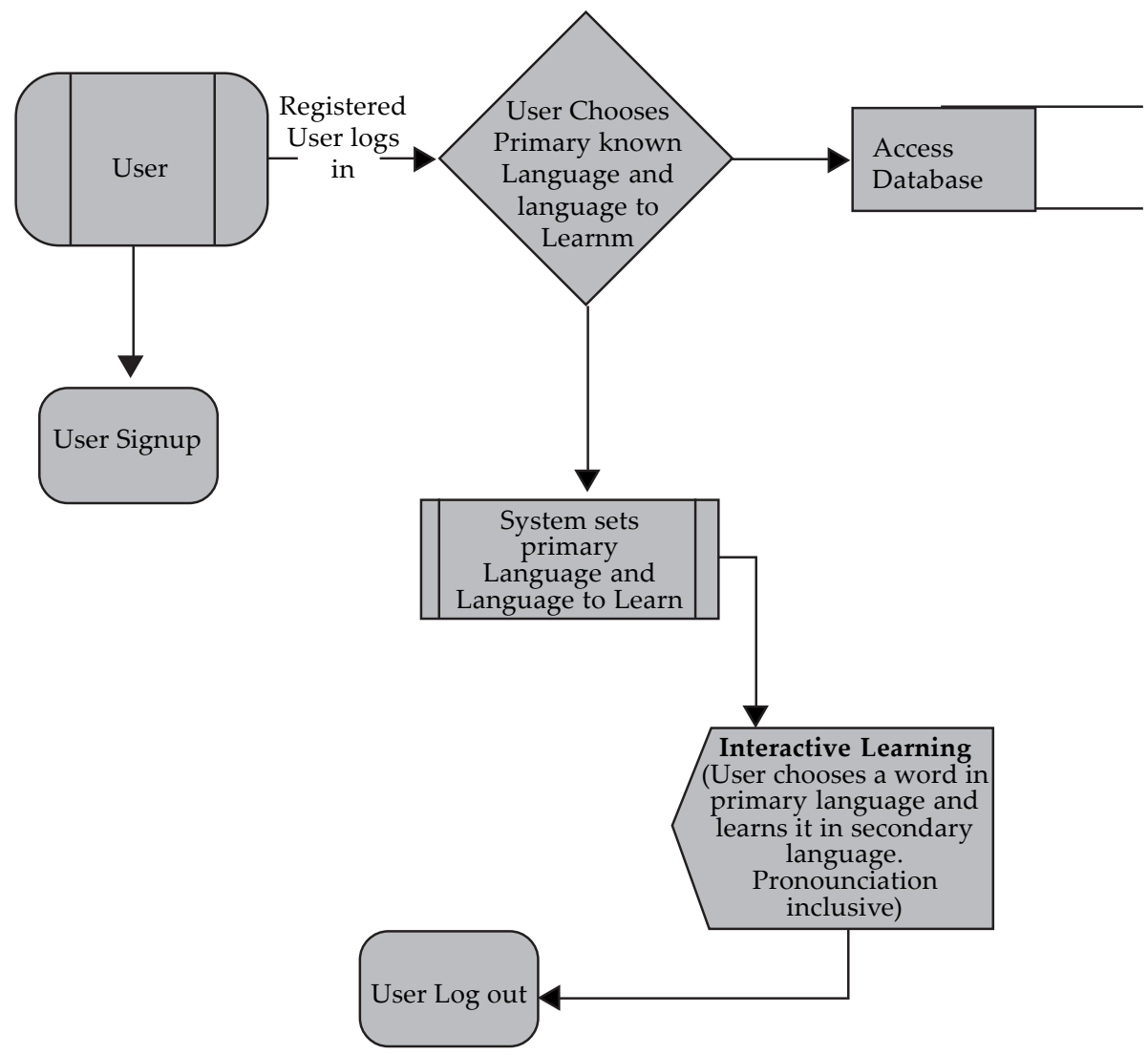




\section{Steps to interrogate the database:}

- User logs in, if user is new, registration option available

- User selects primary language from available languages

- User chooses language to learn and category

- Learning by selecting word or phrase in primary language and learning the word or phrase in the second language

- Pronunciation of phrase or word available during learning

- Navigation utilities incorporated for user to navigate between one category to another, one language to another, backwards and forwards between phrases and words.

The language learner is written in a combination of c\# and ASP.Net. Sound files stored in compressed .wav format and text stored in a simple access D-Base.

\section{Testing phase}

As it is often said, the proof of the pudding is in the eating, and therefore the project was obliged to test its product in the market. Since the software is in its inception stage, we decided to pilot test it within the USIU student, staff and faculty communities. Consequently, we hosted it on a server available to these clients with a view to enabling them test it for its efficacy and aesthetics. The process is ongoing and we hope to refine the software after two months of testing for wrinkles. Currently, the USIU community can access the software and toy with it from wherever they are provided they have Internet connection.

\section{Conclusions}

When South Korea decided forty years ago to invest in Information technology on a 20-year period they had made one of the most important decisions in the life of that country. Today, the country, whose GDP was comparable to Kenya's and behind Ghana's, is one of the leading lights in IT, especially in liquid crystal display (LCD). In the meantime, the country has abandoned the ranks of poor countries where Kenya and Ghana now squarely belong.

Kenya needs to embrace IT, not simply as a consumer, but also as a producer of software that respond to real and perceived needs of society. Importation of hard and software options will never make us pull out of digital backwardness, however cheap it might seem for the time being. Real solution lies in Kenyans being capable and desirous to solve their daily problems via home-grown technologies.

Innovation should be allowed to be the driving force not just in the educational sector but also in the private sector and in our personal lives. Cynicism toward African 
thinking and anything African can be addressed by showing that African innovation is as good as any. Young Kenyans should be encouraged to think of how they can use IT skills to solve first their own personal needs and then society's problems.

The multilingual software is a first step to addressing the dearth of African ingenuity in the domain of IT. It responds to a desire among Kenyans to learn each other's language but more crucially it celebrates the linguistic and therefore cultural diversity of Kenya. It is hoped that once refined, the software will be an invaluable tool to language teachers and learners, domestic and international tourists who may want a quick electronic entry into Kenya's rich languages.

Finally, at a time when Kenya is struggling to understand herself as a country of a rainbow of peoples, the software can be a critical tool in enhancing interethnic understanding thereby creating a favourable milieu for peace to thrive. Unity in diversity is more than desirable now as the country emerges from a Descent into Hell witnessed in December 2007 and January 2008 after a disputed presidential poll.

As IT professionals and enthusiasts, we have a duty to respond to national crises of whatever nature. Here is our humble contribution to make Kenyans rediscover the beauty of their languages and possibly embrace unity in diversity. For non Kenyans, we offer an opportunity to plunge into the waters of Kenya's enthralling linguistic patrimony.

\section{References}

Iraki, F.K., (2004), Cognitive efficiency: The sheng phenomenon in Kenya, Pragmatics, Vol 14.1: 55-68.

Githiora, C. (2002) Sheng: Peer language, Swahili dialect or emerging pidgin? Journal of African Cultural Studies 15.2:159-18

Mucemi, G, et al. (2004), Development of a Kiswahili Text to Speech system, website: llsti.org/documents.htm

Ngugi, P. (2004) Local researchers develop Kiswahili software, article, Daily Nation, 2 September 2004.

Iraki, F.K. (2006), Les technologies de l'information et l'enseignement du FLE au Kenya: le cas du WebCT

\section{Documents and speeches consulted}

How to build a Babel fish, The Economist Technology Quarterly, June $10^{\text {th }} 2006$.

The Ominde Commission Report, 1964, Government of Kenya.

Public Lecture by Mr. Pitroba, IT guru, at USIU in 2006.

http://llsti.org 